\title{
Reframing hydrology education to solve coupled human and environmental problems
}

\author{
E. G. King ${ }^{1}$, F. C. O'Donnell ${ }^{2}$, and K. K. Caylor ${ }^{1}$ \\ ${ }^{1}$ Odum School of Ecology and Warnell School of Forestry and Natural Resources, University of Georgia, Athens, \\ Georgia, USA \\ ${ }^{2}$ Department of Civil and Environmental Engineering, Princeton University, Princeton, New Jersey, USA
}

Correspondence to: E. G. King (egking@uga.edu)

Received: 20 May 2012 - Published in Hydrol. Earth Syst. Sci. Discuss.: 19 June 2012

Revised: 24 September 2012 - Accepted: 6 October 2012 - Published: 6 November 2012

\begin{abstract}
The impact of human activity on the biophysical world raises myriad challenges for sustaining Earth system processes, ecosystem services, and human societies. To engage in meaningful problem-solving in the hydrosphere, this necessitates an approach that recognizes the coupled nature of human and biophysical systems. We argue that, in order to produce the next generation of problem-solvers, hydrology education should ensure that students develop an appreciation and working familiarity in the context of coupled human-environmental systems. We illustrate how undergraduate-level hydrology assignments can extend beyond rote computations or basic throughput scenarios to include consideration of the dynamic interactions with social and other biophysical dimensions of complex adaptive systems. Such an educational approach not only builds appropriate breadth of dynamic understanding, but can also empower students toward assuming influential and effective roles in solving sustainability challenges.
\end{abstract}

\section{Hydrology in the Anthropocene}

Today's world exhibits unprecedented impacts of humans on the planet's hydrological, geochemical, and biological dynamics. The term "Anthropocene" is increasingly used to describe our present geological epoch, drawing clear attention to the ubiquity of human influences on all parts of the Earth system, including physical and biological processes. Human activities are now recognized as a fundamental factor in pedogenesis. The changes in our atmospheric composition since the Industrial Revolution are unique in the history of our planet. Today, human appropriation of water causes one-fourth of river basins to run dry before reaching the ocean (Molden et al., 2007). Seventy percent of terrestrial ecosystems have been transformed by humans (Ellis, 2011), and half of the world's wetland ecosystems have been destroyed (Zedler and Kercher, 2005). There is no ecosystem on Earth that is not impacted by human activity. The hydrosphere - like the atmosphere, lithosphere, or biosphere - does not exist independently of the permeating and often dominating effects of humans.

Looking toward the future, the relationship between humans and the hydrosphere raises troubling concerns. At least 2.4 billion people live in areas considered highly water stressed due to the variability of water abundance in space and time (Oki and Kanae, 2006). Water scarcity threatens not just health and food security, but political stability in arid regions where water resources cross international borders (Amery, 2002). Hydrology is an essential discipline for understanding and managing environmental resources and solving environmental problems. The sustainability of hydrological systems - from a backyard garden, to a municipal water supply or montane watershed, to global climate cycles - cannot be assessed without understanding its dynamic coupling with the human domain. The importance of hydrology in the science of sustainability will continue to grow in the future, as population growth increases demand while climate change is expected to decrease supply (Vörösmarty et al., 2000).

This means that today's hydrology students will be called upon to solve complex problems in the context of linked human-environmental systems. How will hydrological education prepare students to tackle this profound mandate? 
Mastering the fundamentals of hydrology is of course essential. But solving a hydrological problem in isolation is only one component of identifying and evaluating sustainable solutions. Drawing on the most promising current trends in the study of human-environmental systems, we offer ideas, recommendations, and examples of strategies to better prepare hydrology students to understand and solve broader humanenvironment problems. In Sects. 2 and 3, we discuss the value of frameworks that more broadly contextualize hydrological problems and show their relevance to questions of sustainability. Then in Sects. 4, 5, and 6, we consider specific curricular ideas and activities that promote broader thinking and reasoning in hydrology courses. The first example uses familiar and local problems to demonstrate and reinforce the connections between hydrology and humanenvironment systems. The second example is from a field course abroad, which was designed to teach basic hydrology principles while also to deepening students' appreciation of water-related challenges beyond their borders and illustrating how the study of hydrology can be central to solving urgent environmental, sustainability, and development issues. In section 7, we close with a brief discussion of the role of education in empowering future hydrologists to assume transformative roles in building sustainable futures.

\section{Hydrology, human-environmental systems, and sustainability science}

The United States National Academy of Sciences has acknowledged sustainability science as an important emerging multidisciplinary field, which is directed toward understanding the dynamics and behaviors of complex humanenvironment systems (Clark, 2007). In pursuit of this aim, a number of related, mutually compatible frameworks have emerged to integrate disciplines that are typically decoupled, including physical sciences, biological sciences, economics, social sciences, and policy. These frameworks identify key social, biological, and physical variables and the interactions and feedbacks among them, as generally represented in Fig. 1a. Within this general class, individual frameworks vary in which linkages between human and environmental dynamics are of focal importance. For instance the Ecosystem Services framework adopted for the Millennium Ecosystem Assessment focused on human benefits derived from ecological processes (Fig. 1b; Carpenter et al., 2009), while the SocialEcological Systems (SES) Analysis framework focuses on the social interactions and policies that humans employ to manage a particular natural resource (Fig. 1c; Ostrom, 2009).

The commonality and compatibility among such frameworks stem from a few key unifying insights: (a) the dynamics of human systems and biophysical systems are inextricably linked and feed back on one another; (b) these coupled human-environment systems are complex adaptive systems; and (c) as complex adaptive systems, they can be
BIOPHYSICAL $\leftarrow$

$\rightarrow$ SOCIAL
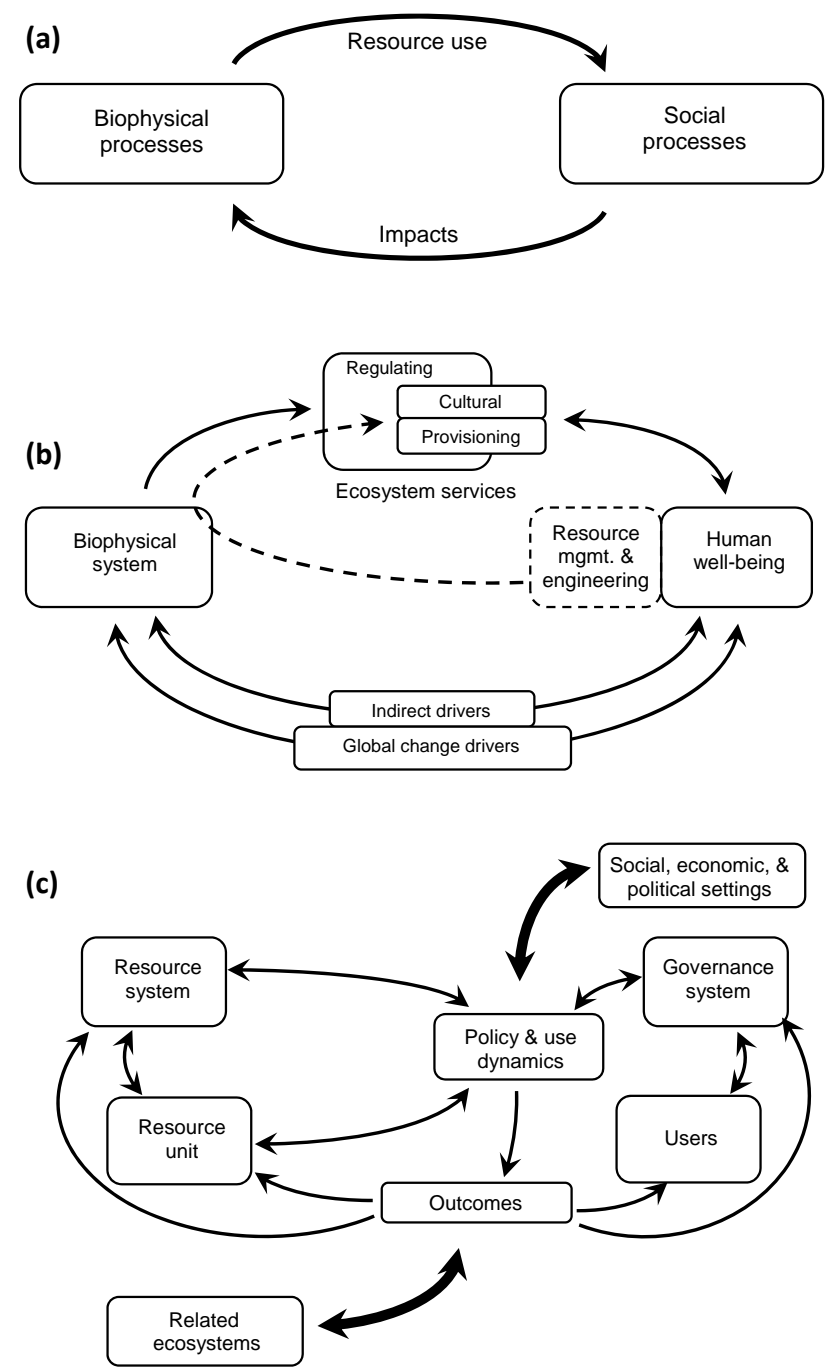

Fig. 1. Schematic diagrams of coupled human-environment systems, illustrating feedback among components in the biophysical and social domains. In each schematic, the left-to-right placement of components reflects their representation of biophysical or social variables. (a) System in its most abstracted form. (b) Millennium Ecosystem Assessment schematic of human-environment system, modified from Carpenter et al. (2009), showing ecosystems services as critical interface between domains and drivers impacting both domains. Role of management and engineering (dashed arrows) added by authors. (c) Social Ecological System (SES) schematic of human-environment system, used by Ostrom (2009) to characterize social ecological dynamics revolving around a specific natural resource (redrawn by authors).

studied using natural or social science approaches to elucidate critical variables and components, the nature of interactions among components, and the system behaviors that emerge as a result of the interactions and feedbacks. The tremendous value of these frameworks is that they allow 
us to understand the dynamics of whole systems based on the interactions of their components. This gives us analytical access to such systems' complex and troublesome emergent behaviors like tipping points, thresholds, whole system transformations, and collapses. Such frameworks are foundational for evaluating sustainability because they afford this ability to evaluate system-wide consequences of biophysical processes and human actions.

Dynamics in the hydrosphere fit into these frameworks because they too are coupled to other biophysical processes and to social dynamics. Pedagogically, connecting hydrology to the science of sustainability entails creating linkages between the dynamics that characterize hydrological science and the broader dynamics that characterize coupled human-environment systems (Wagener et al., 2010). Appreciating that the subject matter of hydrology is embedded in a larger context of causes and effects, which includes human decision-making and generates complex system behaviors, is a primary step in reframing hydrology education to understand environmental problems. We suggest that promoting this appreciation can be achieved by introducing a broader human-environment systems framework as an integral part of any hydrology curriculum, and recursively utilizing the framework in teaching materials, problem sets, and student projects.

\section{Frameworks as lenses}

Mastery of fundamental concepts and techniques is the core purpose of most undergraduate hydrology courses. But covering only fundamentals bounds hydrological problems in a narrow disciplinary context and teaches only one component of identifying and evaluating sustainable solutions. Students need to learn to appreciate and evaluate how resource use and governance impact hydrological systems, and to evaluate how hydrological systems are utilized and valued by humans. This constitutes a wider view, which incorporates inputs and outputs that are not strictly hydrological variables. Even this scope is still limited, however, because the system, albeit more broadly defined, is characterized as a simple throughput, where certain initial conditions generate certain outputs. In reality, human-environment systems rarely behave so deterministically. Instead, links between the hydrosphere and the human-sphere generate feedbacks from hydrological outputs to the management inputs. Another degree of breadth and complexity is needed to understand the actual functioning and thus sustainability of a hydrological system. The connections between management, hydrological systems, and derived services need to be approached dynamically. We refer to these increasingly broad lenses for understanding hydrological problems as narrow, wide, and wide dynamic (Fig. 2).

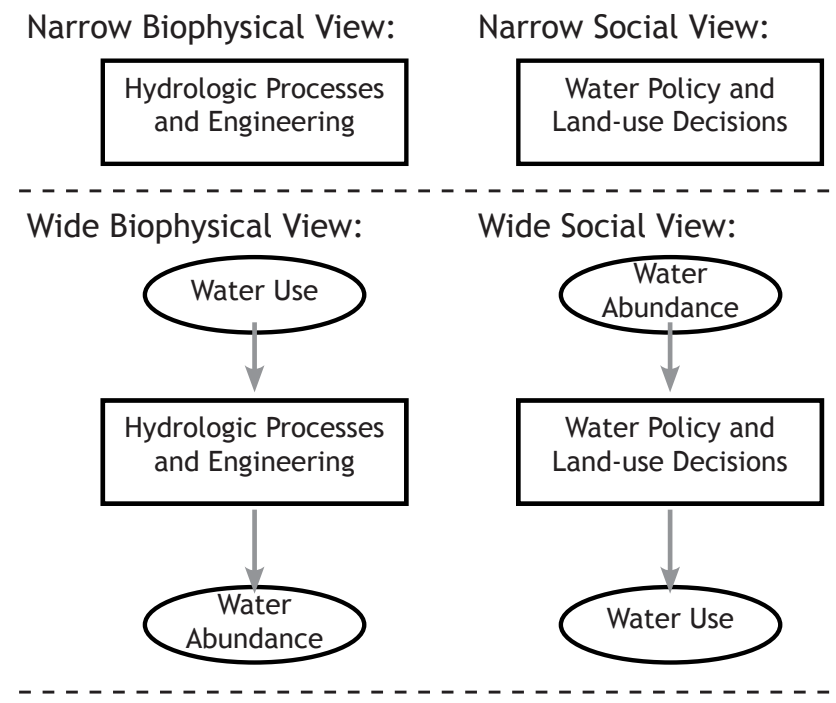

Wide Dynamic View:

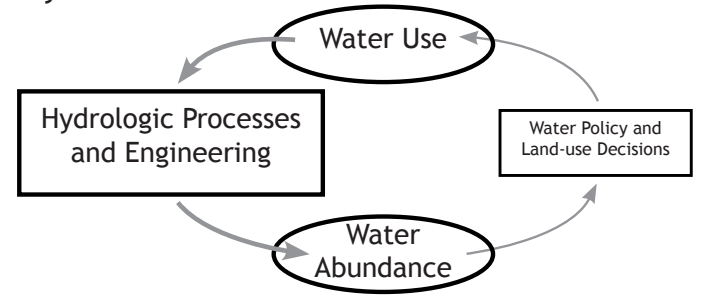

Fig. 2. Diagram illustrating the three lenses through which a component of a human-environment system can be viewed. The top panel shows a narrow disciplinary view of an issue, from either a biophysical or social perspective. External variables and cause-andeffect relationships are viewed through the wide lens, as shown in the middle panel. The bottom panel shows a wide-dynamic view from the biophysical perspective, in which the core component is the focus of the analysis, but the whole system, including feedbacks, is considered.

The many frameworks used in hydrological research variously employ narrow, wide, and wide dynamic lenses. In narrow lens frameworks, the governing equations learned in hydrology curricula utilize hydrological or biophysical variables as input, and calculate hydrological outputs. Hydrological Simulation Program - FORTRAN (Barnwell and Johanson, 1981), for example, is one of the most common basin hydrology simulation models used in the US. The model inputs and outputs are limited to hydrological and geophysical variables. The Water Situation Assessment Model used by the South Africa Department of Water Affairs and Forestry (Dempster et al., 2002) is an example of a wide lens framework, in which the hydrological module is embedded within a larger throughput framework. Human and other ecological dimensions are included as inputs, and the outputs are evaluated to optimize impacts on people and biota. UNESCO's International Hydrological Programme, for example, utilizes a wide-dynamic framework, where the hydrological results of river basin management are translated into 
environmental, social, and economic impacts, which feed back on subsequent water resource regulation via assessment and decision-making (Zalewski, 2002). This approach can facilitate the interface of scientific information and key policy instruments like the European Union Water Framework Directive (Quevauviller et al., 2005). Frameworks such as this embed a module of hydrological processes in the complex adaptive nature of human-environment systems through ecological and decision-making feedbacks. The explicit attention to the role of human activities and decisions embodied in most modern integrative resource management frameworks can clearly demonstrate to students that hydrological processes are a key component, but not the whole story, of water resource management. This notion is at the heart of recent efforts to designate and promote socio-hydrology (Sivapalan et al., 2012), and we feel that instating this dynamic human-hydrosphere perspective through education will be imperative in training the next generation of hydrological problem-solvers.

To complement the hydrology topics presented in courses, we recommend presenting a wide-dynamic humanenvironment framework that is germane to the course subject matter and explicitly reflects the feedbacks between hydrological processes and human dimensions, allowing students to recognize and utilize all three lenses. In other words, hydrology education must teach students to see beyond hydrological systems in isolation, seeing other human and environmental inputs and outputs of the hydrological system, and ultimately recognizing that the system is full of feedbacks that create complex dynamic behaviors. This lattermost point is particularly critical for evaluating sustainability because it allows us to understand trajectories of dynamic change in the system. After all, sustainability is not about how a system functions today, but how today's dynamics and human agency will shape the system through time. We argue that much canonical hydrological training does little to foster this kind of wide dynamic understanding, which future hydrologists will need in order to assume a prominent, effective role in evaluating and promoting sustainability. The burgeoning paradigm of ecohydrology aims to demonstrate dynamic linkages between hydrological and ecological processes (see McClain et al., 2012 in this special issue), while game theory-based decision-making games give students a better appreciation of the principles and challenges of water management from the perspective of social theories regarding public goods and common pool resources (see Hoekstra, 2012; Rusca et al., 2012; Siebert and Vis, 2012 in this special issue). The wide dynamic human-environment perspective spans these innovations in hydrology education, and can serve as an umbrella paradigm representing the reality that hydrological, ecological, and social dimensions are complex, interconnected, and dynamic.

\section{Canonical hydrology teaching practices}

Traditionally, undergraduate hydrology courses consist of lectures that start with a mass or energy balance and derive an equation used to approximate the mass balance in a practical setting. Each lecture is accompanied by an assignment where the students are asked to apply the equation under a set of given conditions. For example, a lecture might present the theoretical basis and derivation of the Penman combination equation for calculating free-water evaporation from meteorological data. An accompanying assignment may then ask the following: Given the following meteorological conditions (average or total daily values for 10 September 1950 at Lake Hefner, OK), compare the open-water evaporation rates given by (a) the mass-transfer, (b) energy-balance, and (c) combination approaches: air temperature $22^{\circ} \mathrm{C}$, relative humidity $68 \%$, wind speed $2.16 \mathrm{~m} \mathrm{~s}^{-1}$, surface temperature $23.7^{\circ} \mathrm{C}$, atmospheric pressure $97.3 \mathrm{kPa}$, incoming shortwave radiation $16.2 \mathrm{MJ} \mathrm{m}^{-2} \mathrm{~d}^{-1}$, albedo $0.057 \mathrm{~m}$, incoming longwave radiation $30.6 \mathrm{MJ} \mathrm{m}^{-2} \mathrm{~d}^{-1}$ (Dingman, 2002).

The question is intended to reinforce the theoretical lessons from lecture by having the students work through the mass-transfer and energy-balance equations in parts (a) and (b), then see how they are combined in the Penman equation in part (c). Each of the equations is given in the textbook, making this a simple "plug-and-chug" exercise. Problems like this are intended to encourage students to think about the link between the three equations, which they may or may not do, as they go through the motions of plugging in values and calculating. The focus on theory and isolated calculations in the assignment represent teaching goals based on a narrow disciplinary view of the concept, neglecting the role of the computational method in evaluating real-world problems. It can be argued that, for those students heading toward a career in water resources engineering and management, knowing when and how to apply the Penman equation to answer questions about human-environment systems would add more pragmatically valuable knowledge.

\section{Wide dynamic hydrology in your backyard: interstate river compacts}

We discuss and illustrate how to extend canonical quantitative exercises to also include the analysis of water resources as a dynamic human-environmental system. To make this extension tractable, accessible, and engaging to students, one tactic is to use a relevant, familiar, or current case study something they can relate to as "in their backyard." That context can then be approached using an appropriate humanenvironment framework, which will highlight and clarify the ways that human and environmental dynamics interact.

The issues surrounding river water resources and rights in the US are highly relevant to most hydrology students at American universities. The SES Framework (Fig. 1c) has 
been used to analyze the sustainability of the interstate river compacts that govern the allocation and management of rivers flowing between states (Schlager and Heikkila, 2009; Heikkila et al., 2011), with river water modeled as a common pool resource. In this framework, rules and actions for governance, management, and enforcement create the feedbacks that link hydrological impacts to subsequent water allocation decisions (Fig. 3a). In addition to being a focus of environmental policy, many western rivers are characterized by extensive engineering, including dams, reservoirs, and irrigation infrastructure. River compacts provide an excellent context for students to see how decision-makers take (or fail to take) engineering decisions and hydrological processes into account as they strive to balance competing interstate water demands, economic pressures, and the compacts' prescribed standards of equity. Analyzing how the coupled dynamics of water resources and river compacts unfold to affect the sustainability of the human-environmental system is a real-world theme that can serve as a touchstone context for a hydrology course without a field component.

Most standard hydrology topics are involved in managed river systems, including basin geomorphology, precipitation, evapotranspiration, infiltration, stream gaging, and open channel flow. Other topics, such as snow and groundwater hydrology, can be addressed by considering externalities to the system, such as how reduced renewable water availability will affect groundwater withdrawals. Individually or in groups, students can choose a river compact that will be the focus of their assignments throughout the course. Devoting time in class or in sections to discussing conclusions reached in the assignments can illustrate how natural features and human activity interact to produce different outcomes in different systems. The analysis of river compacts using a wide dynamic framework provides context for the calculations that students perform in class assignments, both in illustrating the types of issues they are being prepared to address and as a tool for evaluating the consequences of engineering decisions which account for the dynamic nature of hydrologic social-ecological systems.

Continuing with the earlier example of free-water evaporation, the exercise below pursues three learning goals in addition to the traditional aim of teaching students to calculate evaporation rates:

1. Learning to use a "narrow lens" to recognize what kinds of questions are addressed with the computational method, and what kinds of input data are commonly available.

2. Learning to use a "wide lens" to recognize what kinds of decisions are influenced by the results of the computations.
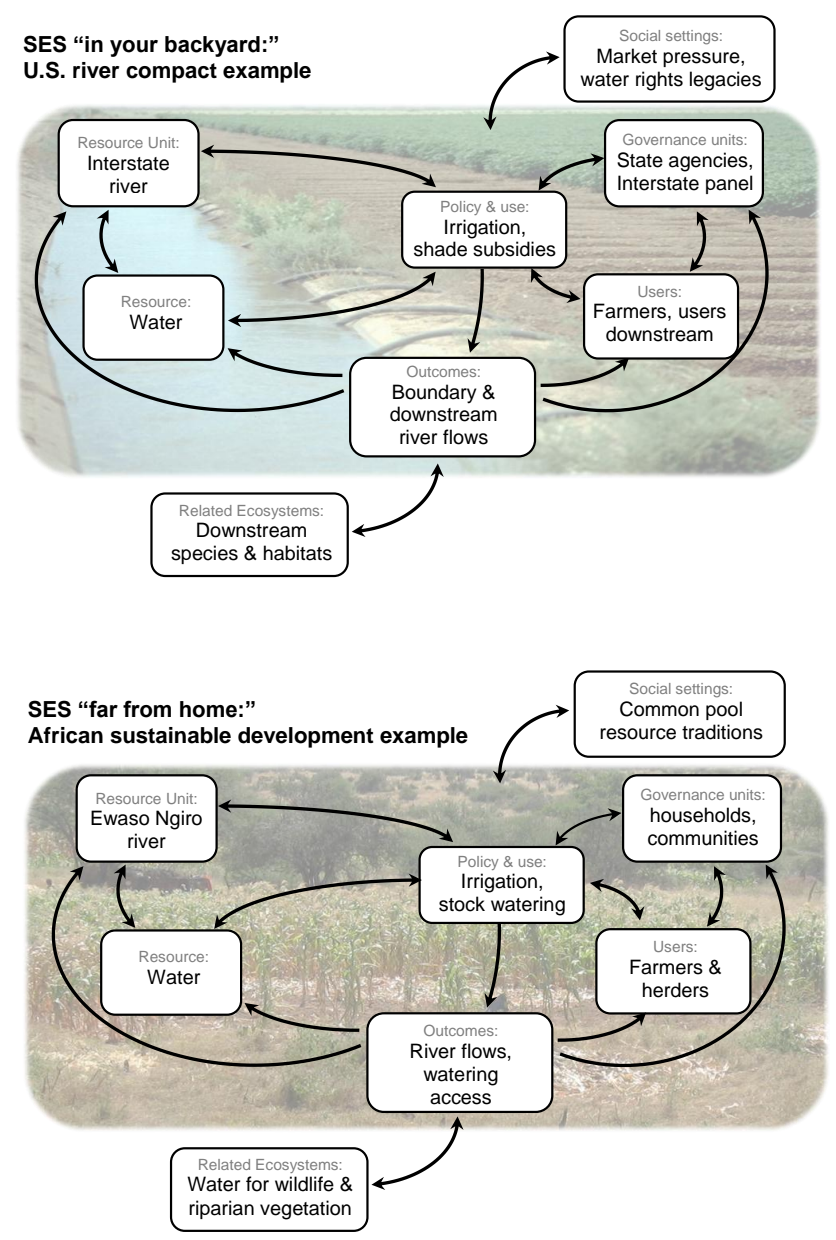

Fig. 3. SES schematic of human-environment system, illustrated with variables specific to the water compact example (a), and the Kenyan river ecohydrology example (b) from the text discussions of potential hydrology assignments "in your backyard" and "far from home," respectively. Photo credits: (a) US Bureau of Reclamation, (b) E. G. King.

3. Learning to use "wide dynamic" lens to understand dynamism in the system and see feedbacks among the variables on either side of the core hydrology problem.

As an example of how a quantitative assignment could incorporate these three goals, the assignment consisting of calculations of free-water evaporation, discussed in the previous section, could be replaced by the following assignment: an environmental group is concerned that low streamflow due to water withdrawals for agriculture is degrading habitat for endangered fish downstream of your water compact region. To increase downstream outflow, the group is lobbying for legislation in the most downstream state of your compact to create a subsidy for farmers to purchase shading covers for their irrigation water reservoirs. The covers save water by reducing evaporative losses. 
a. Consider a single-farm irrigation reservoir in the downstream-most state in your compact, with an evaporative area of $2500 \mathrm{~m}^{2}$. Estimate the annual volume of water saved by installing a shading cover that reduces evaporation by $80 \%$. Select a method for estimating evaporation based on the input data you are able to find from the National Climactic Data Center (http://www.ncdc.noaa.gov/), and the strengths and weaknesses of those data discussed in lecture. Justify your chosen method and any decisions you make about how to average your input data. (Average values for reservoir size and shade cover efficiency from Martínez Alvarez et al., 2009).

b. Assume that there is one irrigation reservoir of the size described in (a) for each 5 hectares of farmland drawing irrigation water from your river, and that all of the farms in the downstream state in your compact use open reservoirs. Using the USGS land cover dataset (http://http://landcover.usgs.gov/), determine the water saved by covering all of the reservoirs, expressed as a percent of average streamflow where the river exits the area governed by your compact.

c. Subsidized shading, if erected by all farmers, can therefore increase river outflow by the percentage calculated in part (b). Ecologists have calculated that an outflow increase of $20 \%$ is necessary to maintain fish habitat. What subsidy or regulatory policies - in the downstream state and in the water compact -would you therefore recommend to ensure adequate outflow for fish conservation? Take into account the current system of irrigation costs and payments in the state, and potentially in upstream states in your compact. Consider how farmers are likely to respond to the recommended policies, and refine your recommendation further.

The first part of the question utilizes the narrow lens, performing a quantitative calculation analogous to the canonical example. However, it brings in a real-world, methodological angle. Since students are working on specific water compacts, they will be interacting with real datasets and making their own decisions about how to determine parameters. The exercise familiarizes students with how to acquire the data necessary to make the calculation and how to interpret and draw conclusions from the result. The extensive online data resources from the National Weather Service and US Geological Survey provide meteorological and hydrological data needed to address a range of hydrologic questions. Working with the online databases gives students first-hand experience with the information used in practice to make management and policy decisions, and familiarizes them with the spatial and temporal scale and resolution of available data. Additionally, they will see which measurements are commonly made, and gain experience in using empirical relationships to attain variables needed to perform calculations. If the course goals include an understanding of field data collection, the students could also be asked to describe how the data they used were collected, as this information is almost always available with online datasets.

Once the students have determined the reduction in evaporation, they use the wide lens to understand how their calculations contribute to an ecological impact in the second part of the assignment. The applicability of many hydrologic computations depends on integrating the results with social, economic, or biological data, and a calculation that demonstrates this may be more useful in reinforcing the concept than an additional isolated hydrologic calculation. Just as meteorological and hydrological data are widely available online, there are also datasets that can help the students address these issues, such as population data from the US Census and data on land cover change from the US Geological Survey. Finally, the students must use the wide dynamic lens to evaluate how the engineering and policy decision functions can alter the conditions under which it was designed, potentially changing their initial policy ideas. Using the coupled human-environment and wide-dynamic approaches encourages them to think about engineering solutions, like the one presented in the assignment, as part of a dynamic system including the natural system, government, and individual decision makers, which could be industries, farmers, or local residents and developers.

Of course, there is not a single set of right answers to the last part of the assignment. Feedback from the teaching staff and, if possible, class time devoted to discussing the various proposed policy approaches is key to achieving the teaching goals of the approach. The assignment also includes necessary simplifications, such as assuming average climatic conditions and a single reservoir size, which should be discussed perhaps in concert with journal articles on the topic. In this case, Martínez Alvarez et al. (2009) present a similar and more detailed analysis for Spain that could serve as an example.

An important goal is to give students a grasp of how complex problems are solved with hydrology, even (and particularly) in introductory courses. Not only can this prove motivational in their continuing studies, it ensures that this kind of thinking is "built in" to their growth as future hydrologists. For many of today's practicing hydrologists, the context of human-environment systems was not included in their classic hydrology education, and may never become a wholly comfortable paradigm. Much like learning a new language later in life, fluency becomes harder to achieve. Yet increasingly today and in the future, hydrologists are called on to communicate effectively and work synergistically to integrate hydrological expertise, management decisions, and evaluations of resource sustainability. 


\section{Wide dynamic hydrology far from home: water and sustainable development}

Some of the most pressing issues in hydrology involve the dramatic challenges facing developing nations in dryland regions, where the sustainable management of water resources is integral to social and economic betterment. To address these issues, hydrologists must be prepared to design and implement new data collection campaigns. Field-based hydrology can provide an ideal setting for this type of training, provided that student projects are framed such that the hydrologic variables are analyzed as part of a dynamic humanenvironment system. To illustrate this approach, we describe a synthesis project from a field ecohydrology course offered on site in the drylands of Laikipia District, Kenya. The curriculum of the course focused on teaching the theory and application of the most common field methodologies in dryland hydrology. The students then implemented the methods and performed basic analyses with the goal of using data to answer a question, rather than taking the traditional approach to "hands-on" learning of performing experiments or measurements to demonstrate a known phenomenon. The students were assigned synthesis projects, in which they used data from multiple field activities to analyze the hydrologic component of a human-ecological system, employing the narrow, wide, and wide dynamic lenses. The following example of a synthesis assignment builds on data from two field exercises that were completed during the semester. The first was a stream surveying and flow measurement exercise. At two points on the Ewaso Nyiro River, the students surveyed cross-sections to determine the average depth and slope of the stream. They also used a flow meter to determine the streamflow. The second field exercise involved installing sap flux probes to measure the transpiration rate of $\mathrm{Aca}$ cia xanthophloea, the dominant tree species surrounding the Ewaso Nyiro, over several days. The synthesis assignment, which follows, was intended to be written up as a report with an introduction, results, supporting figures, conclusions and references.

Develop an assessment of the components of the water cycle that influence the Ewaso Nyiro. Your analysis should address the following questions:

1. Using our channel survey transects and channel profiles, calculate the Ewaso Nyiro discharge at the bridge and at the stream crossing. Utilize Manning's or Chezy's equation to estimate one-dimensional velocity. How do these results compare with the measured discharge values? What are the dimensions of $n$ and $C$ values in the two equations and how would these values change with flow depth?

2. Provide an estimate of total transpiration in our river section by riparian vegetation. Follow the procedure in the sap flux primer and Green and Clothier (1988) to estimate diurnal variation in transpiration rates for Acacia xanthophloea and discuss factors that may influence the cycle. Use estimates of tree density and river length to scale these measurements to total transpiration along the segment.

3. Using micro-meteorological data, estimate the total surface water evaporation occurring between the two streamflow measurements. Select a method for estimating evaporation from the readings or lecture and justify your choice.

4. Provide an estimate of any other potential water losses occurring in the river segment, including human and animal consumption, and decide whether or not these terms are negligible in the water balance.

5. Combine the above estimates in a complete water budget for the segment of the river. Does the equation balance, and, if not, what do you believe are the largest sources of error?

6. In a plan to intensify agricultural production in Laikipia, the local government wants to plant crops on the opposite side of the river from Mpala. The plan involves constructing a small dam from which irrigation canals will be dug. Assume the transpiration rate of the crops is 10 times that of the native trees. Discuss the possible ramifications of the plan for Laikipia and the Ewaso Nyiro.

Parts one through three of the assignment asked the students to use the narrow lens to estimate hydrologic quantities and evaluate measurement techniques. In the fourth and fifth parts, students were expected to draw on their experiences studying and working in the area to estimate the human elements of the water balance (river withdrawals for domestic use, irrigation, and consumption by livestock), as well as the natural ecological factors of consumption by the animals that populate the area. This represents a wide lens approach to the issue.

In the final part of the assignment, students were asked to consider a wide range of effects of dam construction. Two common responses given as ramifications were shifts from herding to agriculture as irrigation water becomes more abundant than watering points for livestock, and changes in wildlife migration patterns when water sources run dry. The students were asked to view the dam construction through a wide dynamic lens, but a complex adaptive framework was not included in the course curriculum. Many of the issues they identified would have feedbacks, such as increased demand for new irrigation sources or disruption of agricultural settlements by migrating wildlife, which must be identified and described to truly understand the system. In retrospect, we feel that priming their evaluation by explicitly presenting a wide dynamic framework would have promoted clearer reasoning and deeper understanding through this final step.

While in this case study students had the extraordinary opportunity to travel to Kenya, the principles can be adapted for 
more typical local situations. For example, the excitement of a foreign locale can be engendered by constructing the exercise as a "virtual field trip", stressing it as an opportunity to explore, have fun, and be creative. Students would utilize existing data as in the "in your backyard" example, but the case study would revolve around an exotic, challenging issue far from home. Students can conduct background research using Internet resources, videos, and news features about their "hydrology holiday destination," stimulating greater curiosity and interest in non-hydrological facets (like local customs, social issues, and the use of water) than their more familiar local environment might. A second adaptation is to maintain the connection between hands-on fieldwork and the wide dynamic lens, except in a local context with ties to a pressing or controversial water use topic. Performing measurements and collecting data first-hand creates a powerful learning experience, and the wide-dynamic analysis report on the exercise (as recommended for the Kenya example) establishes the connections between hydrology in practice and bigger issues of sustainability. This approach maintains the educational goal of linking what students do with their hands in the field to a grasp of a broader, multifaceted resource management issue.

\section{Empowering students by reframing hydrology in a human-environment context}

Evaluating a hydrological issue as the basis for a synthesis report is not novel, of course. However, the above projects offer a notable departure from the more canonical exercise of writing a historical narrative about a hydrological issue, such as a dam construction or a dam failure. First, typical assignments tend to emphasize inputs and outcomes - a nondynamic approach. The social and dynamic aspects of the system are often peripheral to the assignment's thrust, which is not surprising if a broader human-environment framework was not also part of the course material. Secondly, the educational literature is rife with evidence that context matters to learning (Wurdinger and Carlson, 2010). Local contexts that are personally familiar, exotic contexts that stimulate curiosity, and broad dynamic contexts that motivate a student's perceived ability to effect change in the world are three strategies that can be incorporated in hydrology curricula to increase learning effectiveness and student empowerment. Thirdly, typical evaluations of historical cases usually end with a certain known overall outcome. Analyses of current resource management or international development issues, on the other hand, serve to emphasize the unresolved, the open-ended possibilities, and the uncertainty - all dimensions of real issues that can make engineers, hydrologists, and students uncomfortable, but are nevertheless accurate reflections of the world around us. The truth of the matter is that we do not know how to resolve the greatest hydrological challenges in the world. We do not know how to simultaneously ensure hydrological, economic, social and environmental sustainability. In many cases, we do not even know how to assess them. Today's hydrology students must be trained with the gravity of that challenge clear in their mind, in order to focus their educational efforts to rise and meet it. Today we see the simultaneous emergence of ecohydrology, socio-hydrology, and sustainability science as potent fields to grapple with the deep, troubling complexity of water-related issues. The sooner that teachers, textbook authors, and publishers embrace the value of wide dynamic perspectives to enrich hydrological education and empower students, the better we will equip the next generation of hydrologists for their careers in resolving those challenges.

Acknowledgements. We would like to thank T. Wagener, G. Ali and an anonymous reviewer for their helpful comments on a previous draft of this manuscript.

Edited by: T. Wagener

\section{References}

Amery, H. A.: Water wars in the Middle East: a looming threat, The Geographical Journal, 168, 313-323, 2002.

Barnwell, T. O. and Johanson, R.: HSPF: A comprehensive package for simulation of watershed hydrology and water quality, in: Nonpoint Pollution Control: Tools and Techniques for the Future, Interstate Commission on the Potomac River Basin, Rockville, MD, 1981.

Carpenter, S. R., Mooney, H. A., Agard, J., Capistrano, D., DeFries, R. S., Díaz, S., Dietz, T., Duraiappah, A. K., Oteng-Yeboah, A., Pereira, H. M., Perrings, C., Reid, W. V., Sarukhan, J., Scholes, R. J., and Whyte, A.: Science for managing ecosystem services: Beyond the Millennium Ecosystem Assessment, Proc. Natl. Acad. Sci., 106, 1305-1312, doi:10.1073/pnas.0808772106, 2009.

Clark, W. C.: Sustainability science: a room of its own, Proc. Natl. Acad. Sci., 104, 1737-1738, 2007.

Dempster, C. E., Kock, J., and Mare, H. G.: Yield Analysis. March 2002. Report No. PB B100/00/0398 compiled by the BKS (Pty) Ltd / Jakoet \& Associates / Wates, Meiring \& Barnard (Pty) Ltd Consortium as part of the Development of an Integrated Water Resources Model of the Upper Olifants River (Loskop Dam) Catchment study for the Department of Water Affairs and Forestry, Directorate: Project Planning, Pretoria, South Africa, 2002.

Dingman, S. L.: Physical Hydrology, 2nd Edn., Prentice Hall, Upper Saddle River, New Jersey, USA, 2002.

Ellis, E. C.: Anthropogenic transformation of the terrestrial biosphere, Philos. T. R. Soc. A, 369, 1010-1035, 2011.

Green, S. and Clothier, B.: Water use of kiwifruit vines and apple trees by the heat-pulse technique, J. Exp. Bot., 39, 115-123, 1988.

Heikkila, T., Schlager, E., and Davis, M. W.: The Role of CrossScale Institutional Linkages in Common Pool Resource Management: Assessing Interstate River Compacts, Policy Stud. J., 39, 121-145, 2011. 
Hoekstra, A. Y.: Computer-supported games and role plays in teaching water management, Hydrol. Earth Syst. Sci., 16, 2985-2994, doi:10.5194/hess-16-2985-2012, 2012.

Martínez Alvarez, V., Leyva, J. C., Maestre Valero, J., and Górriz, B. M.: Economic assessment of shade-cloth covers for agricultural irrigation reservoirs in a semi-arid climate, Agr. Water Manage., 96, 1351-1359, 2009.

McClain, M. E., Chícharo, L., Fohrer, N., Gaviño Novillo, M., Windhorst, W., and Zalewski, M.: Training hydrologists to be ecohydrologists and play a leading role in environmental problem solving, Hydrol. Earth Syst. Sci., 16, 1685-1696, doi:10.5194/hess-16-1685-2012, 2012.

Molden, D., Frenken, K., Barker, R., De Fraiture, C., Mati, B., Svendsen, M., Sadoff, C., and Finlayson, C.: Trends in water and agricultural development, in: Water for food, water for life: a comprehensive assessment of water management in agriculture, edited by: Molden, D., Earthscan, London, UK and International Water Management Institute, Colombo, Sri Lanka, 57-89, 2007.

Oki, T. and Kanae, S.: Global hydrological cycles and world water resources, Science, 313, 1068-1072, 2006.

Ostrom, E.: A general framework for analyzing sustainability in social-ecological systems. Science, 325, 419-422, 2009.

Quevauviller, P., Balabanis, P., Fragakis, C., Weydert, M., Oliver, M., Kaschl, A., Arnold, G., Kroll, A., Galbiati, L., Zaldivar, J. M., and Bidoglio, G.: Science-policy integration needs in support of the implementation of the EU Water Framework Directive, Environ. Sci. Policy, 8, 203-211, doi:10.1016/j.envsci.2005.02.003, 2005.

Rusca, M., Heun, J., and Schwartz, K.: Water management simulation games and the construction of knowledge, Hydrol. Earth Syst. Sci., 16, 2749-2757, doi:10.5194/hess-16-2749-2012, 2012.
Schlager, E. and Heikkila, T.: Resolving Water Conflicts: A Comparative Analysis of Interstate River Compacts, Policy Stud. J., 37, 367-392, 2009.

Seibert, J. and Vis, M. J. P.: Irrigania - a web-based game about sharing water resources, Hydrol. Earth Syst. Sci., 16, 2523-2530, doi:10.5194/hess-16-2523-2012, 2012.

Sivapalan, M., Savenije, H. H. G., and Bloeschl, G.: Sociohydrology: A new science of people and water, Hydrol. Process., 26, 1270-1276, 2012.

Vörösmarty, C. J., Green, P., Salisbury, J., and Lammers, R. B.: Global water resources: vulnerability from climate change and population growth, Science, 289, 284, doi:10.1126/science.289.5477.284, 2000.

Wurdinger, S. D. and Carlson, J.: Teaching for experiential learning: five approaches that work, R\&L Education, 2010.

Wagener, T., Sivapalan, M., Troch, P. A., McGlynn, B. L., Harman, C. J., Gupta, H. V., Kumar, P., Rao, P. S. C., Basu, N. B., and Wilson, J. S.: The future of hydrology: An evolving science for a changing world, Water Resour. Res., 46, W05301, doi:10.1029/2009WR008906, 2010.

Zalewski, M.: Ecohydrology - the use of ecological and hydrological processes for sustainable management of water resources, Hydrolog. Sci. J., 47, 823-832, doi:10.1080/02626660209492986, 2002.

Zedler, J. B. and Kercher, S.: Wetland resources: status, trends, ecosystem services, and restorability, Annu. Rev. Environ. Resour., 30, 39-74, 2005. 